\title{
MODELING OF NITROGEN TRANSPORT IN VARIABLY SATURATED SOILS
}

\author{
KARRA, R. - MASLOUHI, A. ${ }^{*}$ - BAMBA, Y. O. \\ Laboratory for Natural Resources and Environment, Department of Physics, Faculty of \\ Sciences, Ibn Tofail University \\ B.P. 242, 14000 Kenitra, Morocco \\ (phone: +212-5-3732-9200; fax: +212-5-3737-4052) \\ *Corresponding author \\ e-mail:maslouhi_a@yahoo.com \\ (Received $12^{\text {th }}$ Oct 2017; accepted $12^{\text {th }}$ Feb 2018)
}

\begin{abstract}
Nitrate contamination in irrigation groundwater is a serious worldwide problem. The aim of this paper is to focus on the mathematical modeling of the water flow and the reactive solute in porous media. In this approach, a mathematical model based on a single flow equation is developed; which can be used for both unsaturated and saturated zones regarded as a single continuum. The model is based on the finite element method using the Freefem ++ code and generates a solution for two-dimensional water flow and solute transport equations. The self-adaptive meshing capability of the code has confirmed that the capillary fringe is a zone with complicated physical processes. The nitrogen transformations in the soil were simplified using parameters that can be calculated from easily measured chemical soil properties or obtained from the literature. This study shows the interest of modeling various chemical, physical and biological processes that influence the fate of nitrogen in the agricultural soils for evaluating the groundwater contamination by nitrates. The nitrogen simulation shows that in the saturated zone, the flow is mostly loaded by the nitrate and the ammonium nitrogen has an insignificant effect on the solute transport in the aquifer. The validity of the model is proved by a good-fit between computed and observed data measurements in the laboratory-scale physical model. In general, the numerical model constitutes a rapid tool to predict with an excellent precision the water flow and the reactive solute evolution in groundwater.
\end{abstract}

Keywords: FreeFem++, mesh adaptation, nitrate, pollution, porous media, simulation, water

\section{Introduction}

Groundwater contamination by nitrates in Mnasra aquifer has generated widespread interest in the last few years (Saâdi et al., 1999; Ibnoussina et al., 2006), due to concerns raised by the increasing level of degradation of water quality and the related toxicological consequences of nitrates for human health (Bryan, 2011). With the intensification and modernization of agriculture, the amounts of nitrogen fertilizers are constantly increasing (Manzoni and Porporato, 2009; Shekofteh et al., 2013). Contamination of groundwater and surface water by excess nitrates resulting from increasing urbanization and intensified agricultural activities is a global concern (Deb et al., 2016). The Gharb water table, whose concentrations exceed the $200 \mathrm{mg} / \mathrm{l}$ in many wells, is beyond the allowed limit of $50 \mathrm{mg} / \mathrm{l}$ established by the World Health Organization (Saâdi and Maslouhi, 2003). Indeed, the massive use of nitrogen fertilizers has been implicated in the release of greenhouse gases into the atmosphere. In France (large agriculture producer), the average values of agricultural nitrogen balances show an excess of 1.5 to 2 million tons of nitrogen.

If nitrogen migrates to bodies of water or lakes, it can cause algal blooms, oxygen deprivation for many species of fish in aquatic systems. In Italy, agriculture accounts for 
$68 \%$ of the nitrogen supply in the Po river. Lake Victoria has experienced increased eutrophication over the last 50 years, at which high concentrations of nitrate is considered a major contributing factor (Bryan, 2011). Wastewater infiltration basins in the Reedy Creek Improvement District present a significant risk of aquifer contamination due to the nitrate concentration of the water applied to the basin.

Excessive concentrations of nitrate in drinking water cause methaemoglobinaemia, a blood disorder that mainly affects infants under 6 months of age ("blue baby" syndrome). Consumption of nitrate-polluted water has also been implicated circumstantially in the increased risk of gastrointestinal cancer in adults. The potential impact of contamination by fertilizers and pesticides on water supply led to the development of models to simulate the soil and plant system.

Saâdi and Maslouhi (2003) developed a mechanistic model to predict the water runoff and transformations of nitrogen in the unsaturated soil in the agricultural area of Mnasra. Therefore, the knowledge of the hydraulic soil properties is essential for the assessment of the hydrological processes (Bagarello and Iovino, 2012; Moret-Fernández et al., 2015).

Water flow and nitrogen transport in a porous unsaturated-saturated medium constitute a difficult phenomena to study (i.e. Nonlinear Differential Equations). Conventional models often use the coupled unsaturated-saturated flow process. Groundwater flow in the saturated zone is described by a horizontal flow, whereas the flow in the unsaturated zone is considered vertical. The unknown, a priori, position of the water table makes the coupled problem difficult to solve (Maslouhi et al., 2009). Study of water flow and solute transport in the unsaturated and saturated zones has often been carried out by using distinct mathematical models, which are applied separately in each zone (Dupuy et al., 1997; Lindström et al., 2010). This kind of approach is based on a technique of artificial coupling, connecting the two zones, which often generates numerical disturbances at the unsaturated-saturated interface (i.e. the water table).

Diaw et al. (2001) performed a study of one-dimensional water flow through the unsaturated-saturated zone. However, Vachaud et al. (1973) first investigated the twodimensional steady state flow through the unsaturated-saturated zones. In this approach, a mathematical model based on a single flow equation was developed. It can be used for both unsaturated and saturated zones, regarded as a single continuum. The purpose of this study is to calibrate and verify the developed model with the measurements obtained from soil tank experiment; and to simulate the water flow and nitrogen transport in the porous medium. This numerical simulation studies the unsteady-state pressure distributions and nitrogen concentrations for variably-saturated soil.

The transport of mineral substances like nitrate nitrogen $\mathrm{NO}_{3}{ }^{-}-\mathrm{N}$ and ammonia nitrogen $\mathrm{NH}_{4}^{+}-\mathrm{N}$, is described by the convection-dispersion equation (Saâdi et al., 1999; Filipović et al., 2014). Several mathematical models with different degree of nonlinearity and different level of complexity describe the process of mineralization that occurs at the soil surface, affected by physical and biological interaction (Maggi et al., 2008; Manzoni and Porporato, 2009). The process of mineralization and nitrification in the unsaturated zone are described here by a simplified first order kinetics (Butturini et al., 2000; Saâdi and Maslouhi, 2003). The Hénin-Dupuis model allows the description of the process of mineralization. It is a mono-compartmental model with the benefit of using a simple formula (ordinary differential equation). Its parameters are affected by climatic conditions, soil characteristics and management practices (Ibnoussina et al., 
2006). The adsorption of ammonium $\mathrm{NH}_{4}{ }^{+}$ions in the soil is described by a linear isothermal equilibrium and the contribution of fertilizer is described by a condition of mass flow at the surface (Bechtold et al., 2006; Deb et al., 2016). In this case, the used models have the advantage of using a reduced number of parameters for the model calibration. Furthermore, the parameters are calculated from easily measured chemical soil properties or obtained from the literature. Riparian areas can reduce nitrogen inputs to aquatic systems through plant uptake and microbial denitrification. For example, denitrification "hot spots" can be found along root canals where moisture and organic matter content are high or in anaerobic locations. In a field case, the nitrate concentration would not be well simulated by the model in riparian zones or areas with high denitrification (Maggi et al., 2008). Indeed, this process can lead to a real transformation of nitrogen to gaseous forms (up to 5\%). In laboratory experiment, denitrification was assumed negligible.

The model also presents the flexibility to integrate other physico-chemical processes. Numerical modeling is based on a finite element computer Freefem ++ code (Hecht, 2012). This code was adapted to the equations used in this study, namely: the Richards equation to study the water flow in the unsaturated-saturated domain and the transport equation, of the advection-diffusion type for the study of nitrogen transfer in two compartments of the porous media. The advantage of using this code is the self-adaptive mesh generation; it improves the accuracy of the automatically refined domain (Belhamadia et al., 2014). Therefore, the information in the vicinity of the singular areas is more accurate (infiltration area, free surface, capillary fringe) while saving on computation and simulation time. The memory and space gain is significant when the simulations are realized on a large scale domain (Hecht, 2012). Freefem ++ also takes advantage of the multi-core processor structure and parallel computing. The numerical model was validated using experimental data performed at the scale model, and allowed to predict with high accuracy the position of the free surface of the water table and the advancement of a reactive solute in the two compartments. The results of this study can be helpful to prevent the nitrogen pollution, ensure the safety of water table supply, the sustainability of water resources and an auxiliary instrument for decision making in water management.

\section{Materials and methods}

\section{Study domain}

In the laboratory experiments, a slab of soil with a length of $600 \mathrm{~cm}, 200 \mathrm{~cm}$ of depth and $30 \mathrm{~cm}$ of width was used. A rainfall simulator was designed as a source of flow in an infiltration band of $100 \mathrm{~cm}$. To impose a constant hydraulic head in the outlet, a reservoir was attached to the slab. In the $x O z$ coordinate system, the $O x$ axis correspond to the surface of the ground, the $O z$ axis being vertically downward and the origin $O$ being in the infiltration band center. The problem is assumed as a plane one with a symmetry about the $O z$ axis; the problems of transfers can be studied only in the half of the system. Assuming a horizontal water table established on a thickness $e$ above an impermeable bottom at a depth of $e_{0}$. A constant infiltration flow of $q_{0}$ is applied to the surface of the ground. Furthermore, the reservoir is assumed between two parallel trenches of the same length as the slab, where the piezometric level is maintained at a constant depth $e_{0}$. A Marriotte bottle system was used to keep a constant inlet flux and 
an electric pump to maintain water table level in the outlet. Figure 1 shows the geometry of the studied system. The flow domain boundaries are:

- A portion of the upper horizontal surface (ground surface) on which is applied a constant flux $q_{0}=15 \mathrm{~cm} / \mathrm{h}$, causing infiltration. The infiltration band will simulate a canal of irrigation or an artificial catchment basin. The value of $q_{0}$ is chosen to be smaller than the saturated hydraulic conductivity of this soil.

- A nozzle rainfall simulator is used. It is delimited by a steel rectangle of $5 \mathrm{~cm}$ height. The water table level in the outlet is imposed to $H_{0}$.

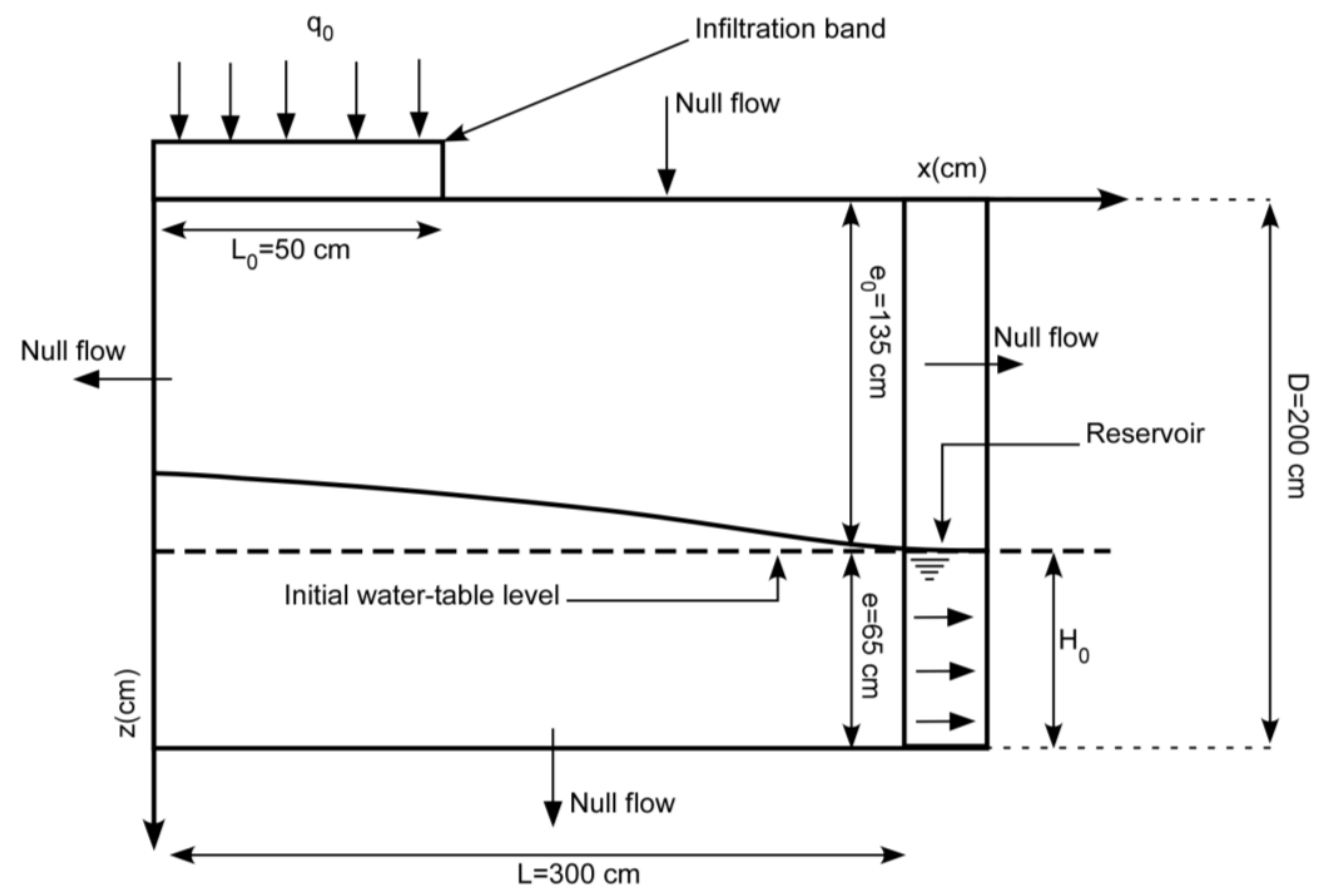

Figure 1. Schematic representation of the flow domain

The sample soil was taken from a field in the Mnasra zone. The soil used is a fine sand of fairly regular grain-size distribution. Soil hydraulic characteristics and properties are listed in Table 1. In order to avoid nitrogen contamination, the chosen field has not been fertilized or manured for at least 12 months.

Two approaches can be used for in situ hydrodynamic soil characterization. The direct method based on experimental measures combined with infiltration models or the inverse method that identifies the hydrodynamic parameters from measurements. The inverse method is not covered by this study. In the direct method, several experimental techniques are required to determine the parameters. As part of this experiment, a disk infiltrometer is used to measure the soil hydraulic properties near saturation. Its advantage lies in its in situ use, its rapid implementation and the numerous studies on it (Moret-Fernández et al., 2015; Rezaei et al., 2016). It allows a potential range between [0-200 $\mathrm{mm}]$, the potential range, although reduced, integrates the possible flow configurations between the relative water content and saturated water content. It gives a specific advantage compared to other devices for soil hydraulic conductivity measurements, such as the Guelph Permeameter and Compact Constant Head Permeameter CCHP (Cheng et al., 2011; Reynolds and Jeffrey, 2012). 


\section{Hydrodynamic characterization}

Several empirical models are used to relate the water content, pressure head and hydraulic conductivity; their parameters specify different types of soils. The most common of these forms are the Brooks-Corey (1964) and Genuchten (1980), although many more have been presented in the literature over the past two decades.

The Mualem (1976) and Genuchten (1980) model is widely used to describe the relationship between the pressure head and water content, as shown in Equation 1:

$$
\frac{\theta(h)-\theta_{r}}{\theta_{s}-\theta_{r}}=\left[1+(\alpha h)^{n}\right]^{-m}
$$

$\theta$ is the volumetric water content $\left(L^{3} L^{-3}\right), h$ is the pressure head $(L), \theta_{s}$ is the saturation water content scale parameter, which is called the volumetric water content at natural saturation $\left(L^{3} L^{-3}\right) . \theta_{r}$ is the residual water content $\left(L^{3} L^{-3}\right), \alpha\left(L^{-1}\right), n(-), m(-)$ are shape parameters related to the pore size distribution. They are subjected to the constraint of $m=1-k_{m} / n$, where $k_{m}$ is an integer value initially introduced by van Genuchten to calculate closed-form analytical expressions for the hydraulic conductivity function when substituted in the predictive conductivity model of Mualem.

The Brooks-Corey hydraulic model is also widely accepted, the unsaturated hydraulic conductivity function is based on Equation 2:

$$
K(h)=K_{s}\left(\frac{\theta-\theta_{r}}{\theta_{s}-\theta_{r}}\right)^{\eta} \quad \text { for } h<h_{e}
$$

with: $\eta=2 / \lambda+3$.

$K$ is the hydraulic conductivity $\left(\mathrm{LT}^{-1}\right), h_{e}$ is the air entry pressure and $\lambda$ is a positive pore size distribution index, being small for clay soils and large for sandy soils.

According to Bagarello and Iovino (2012), only the combination of van Genuchten water retention equation $(E q .1) h(\theta)$, based on Burdine theory (i.e. $\left.k_{m}=2\right)$ together with the Brooks and Corey conductivity equation ( $E q$. 2) stays valid for a large type of soils encountered in practice without becoming inconsistent with the general water infiltration theory. This is due to the rather limiting constraint which exists for the shape parameter $m$ when using Mualem theory (i.e. $k_{m}=1$ ): $0.15 \leq m \leq 10$.

Moreover, to get the curves $K(h)$ and $\theta(h)$, the models of van Genuchten and BrooksCorey are adjusted on the points of experimental measures. To minimize the error between the simulated and observed values, the adjustment is performed according to the Levenberg-Marquardt algorithm (Rezaei et al., 2016). The Levenberg-Marquardt method is a standard technique for solving nonlinear least squares problems. Equation 3 is the appropriate form of the objective function $\Phi$ :

$$
\min \Phi(h,(\theta, K))=\frac{\sum_{i=1}^{r}\left[\theta_{\text {mes }}\left(h_{i}\right)-\theta_{\text {fit }}\left(h_{i}\right)\right]^{2}+\sum_{i=1}^{r}\left[\ln \left(K_{\text {mes }}\left(h_{i}\right)\right)-\ln \left(K_{\text {fit }}\left(h_{i}\right)\right)\right]^{2}}{r, \sigma_{s}^{2}}
$$


where $\theta_{\text {mes }}$ and $\theta_{\text {fit }}$ are the measured and predicted water content, $K_{\text {mes }}$ and $K_{\text {fit }}$ are the measured and predicted hydraulic conductivity, $\sigma_{s}{ }^{2}$ are variations of the measured data and $r$ is the number of observations.

Thus, by undertaking several tests at different pressure heads, the $h(\theta)$ and $K(h)$ curves were obtained (Fig. 2).
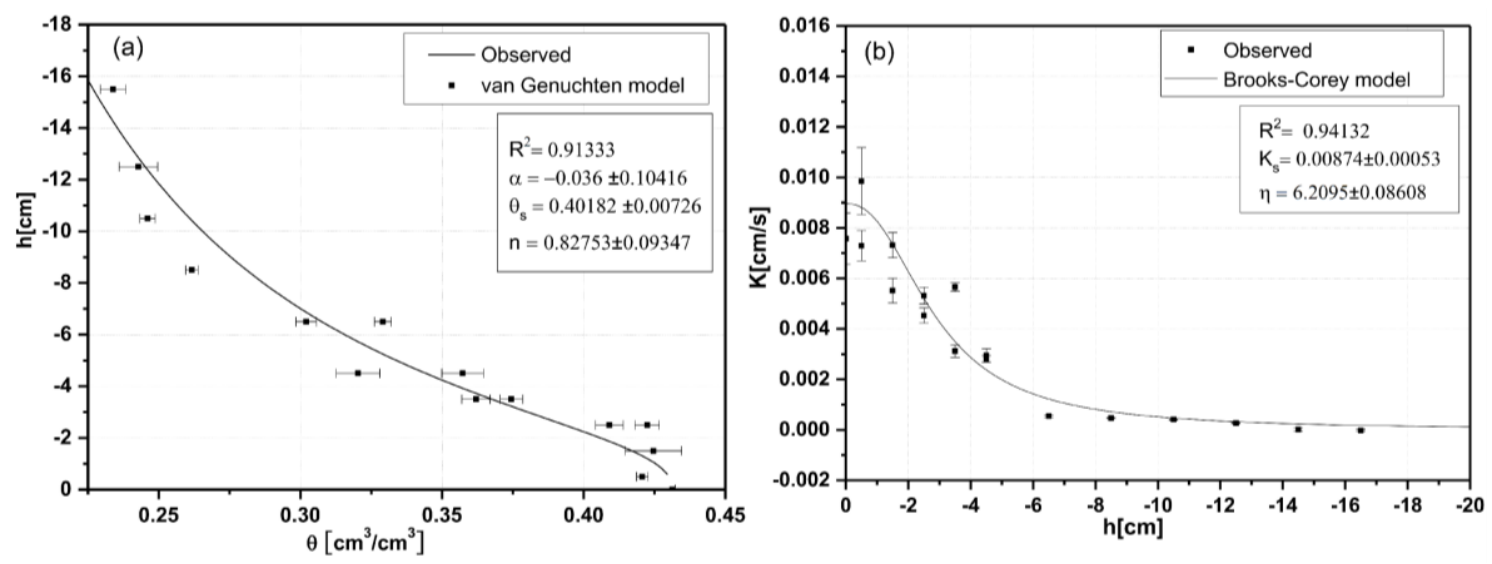

Figure 2. Suction and hydraulic conductivity curves for the studied soil

The combination of van Genuchten and Brooks-Corey models give excellent agreement between measured and calculated (fitted) values with $R^{2}=0.94$ for $K(h)$ and $R^{2}=0.91$ for $h(\theta)$.

\section{Water flow in unsaturated-saturated porous media}

The $2 \mathrm{D}$ equation of flow in the case of the unsaturated zone is obtained by combining the generalized Darcy equation, which expresses the law of flows proportionality, to the mass balance equation. The unsaturated and saturated zones can be considered as a single continuum domain. Equation 4 is used in the two zones has the form of the Richards equation:

$$
C(h) \frac{\partial h}{\partial t}=\frac{\partial}{\partial x}\left(K(h) \frac{\partial h}{\partial x}\right)+\frac{\partial}{\partial z}\left(K(h)\left(\frac{\partial h}{\partial z}-1\right)\right)-S
$$

with $C(h)=\partial \theta / \partial h$ is the specific moisture capacity $\left(L^{-1}\right), t$ is the time $(T), S$ is a sink/source term $\left(T^{-1}\right)$ and $z$ is the depth $(L)$.

-In the case of the vadose zone:

The sink term does not apply, so the classical Richards equation for the unsaturated zone becomes (Eq. 5):

$$
C(h) \frac{\partial h}{\partial t}=\nabla(K(h) \nabla(h-z))
$$

-In the case of the saturated zone:

$C=S_{s}$ is the specific storativity of a porous medium and $K(h)=K_{s}$ is the saturated hydraulic conductivity $\left(L T^{-1}\right)$. 
Thus, the diffusivity equation characterizing the transient state flow in a saturated zone as described in Equation 6:

$$
S \frac{\partial h}{\partial t}=\frac{\partial^{2} h}{\partial x^{2}}+\frac{\partial^{2} h}{\partial z^{2}}
$$

with: $S=\frac{S_{s}}{K_{s}}$ the total storativity of the porous medium.

At the soil surface, Equation 5 can be subject either to a flux boundary condition (Neumann, Eq. 7) or a pressure head boundary condition (Dirichlet, Eq. 8):

$$
\begin{gathered}
q_{1}=q(0, t)=-K(h)\left(\left.\frac{\partial h}{\partial z}\right|_{z \rightarrow 0^{+}}-1\right) \\
h(0, t)=h_{1}
\end{gathered}
$$

where: $q_{1}$ and $h_{1}$ are respectively the Darcian water flux or water flux density $\left(L T^{1}\right)$ and the pressure head at the soil surface. At natural field conditions, they can have either positive or negative values. $q_{1}$ is given by Equation 9:

$$
q_{1}=\frac{P}{\Delta t}
$$

where: $P$ is rainfall and/or irrigation $(L)$, during the time increment $\Delta t(T)$.

\section{Nitrogen transport equation}

The transport of mineral nitrogen in unsaturated soil is described by the 2D convection-dispersion equation in its most general form (Filipović et al., 2014) as shown in Equation 10:

$$
\begin{aligned}
\frac{\partial\left(\rho_{d} S_{i}\right)}{\partial t}+\frac{\partial\left(\theta C_{i}\right)}{\partial t} & =\frac{\partial}{\partial x}\left(\theta D_{\mathrm{ap}} \frac{\partial C_{i}}{\partial x}\right)-\frac{\left.\partial\left(Q_{x} C_{i}\right)\right)}{\partial x} \\
& +\frac{\partial}{\partial z}\left(\theta D_{\mathrm{ap}} \frac{\partial C_{i}}{\partial z}\right)-\frac{\partial\left(Q_{z} C_{i}\right)}{\partial z}+\sum_{j} T_{i, j}\left(C_{i}, S_{i}\right)
\end{aligned}
$$

where $C_{i}\left(M L^{-3}\right)$ and $S_{i}\left(M M^{-1}\right)$ are the concentrations of the element (i) associated with liquid and solid phases respectively, $\rho_{d}$ is the density of the dry soil $\left(M L^{-3}\right), T_{i, j}$ is the rate of loss or creation of the element $(i)\left(M L^{-3} T^{-1}\right)$, the index $(j)$ is associated to the various reactions which the element $(i)$ in the soil can undergo, $D_{a p}$ is the apparent diffusion-dispersion coefficient of the element $(i)\left(L^{2} T^{-1}\right)$ with $D_{a p}=\xi_{i} Q / \theta+D_{0, i}$ where $\xi_{i}$ and $D_{0, i}$ are respectively the dispersivity $(L)$ and molecular diffusion $\left(L^{-2} T^{1}\right)$ of the element $(i)$ in the soil. $Q_{x}$ and $Q_{z}$ are the Darcy flow $\left(M T^{-1}\right)$ to $x$ and $z$ directions respectively. Knowledge of water content, and water flux density is obtained from solutions of the Richards equation. When dealing with nitrogen transport and 
transformations in an unsaturated soil, the chemical species $(i)$ are the nitrate nitrogen $\mathrm{NO}_{3}{ }^{-}$and ammonium nitrogen $\mathrm{NH}_{4}{ }^{+}$(Hanson et al., 2006).

Nitrification and soil organic nitrogen mineralization processes are modeled using first-order rate kinetics as described by Saâdi et al. (1999) and Maggi et al. (2008). The latter process is described by the Hénin-Dupuis's simple model in Equation 11 (Saâdi and Maslouhi, 2003):

$$
\frac{d N_{\text {org }}}{d t}=-k_{\min }\left(N_{\text {org }}-N_{\infty}\right)
$$

where $N_{\text {org }}$ is the instantaneous soil organic nitrogen $\left(M L^{-2}\right), N_{\infty}$ is the organic nitrogen supplied to the ploughed layer such as roots and straw. $k_{\min }$ is the first order rate conditional constant $\left(T^{1}\right)$ which is specific to the climate and crops developed in each region.

The nitrification process is modeled as stated by several authors (e.g. Butturini et al., 2000; Shekofteh et al., 2013) in Equation 12:

$$
\frac{d C_{N_{3}^{-}}}{d t}=k_{\mathrm{nit}} C_{N H_{4}^{+}}
$$

where $k_{n i t}$ is the first order rate conditional constant $\left(T^{-1}\right)$, which can easily be found in literature (Ibnoussina et al., 2006).

The ammonium nitrogen $\mathrm{NH}_{4}^{+}$adsorption by negatively charged clay particles and organic colloids in the soil is described by a linear equilibrium isotherm Equation 13 (Deb et al., 2016):

$$
S_{N_{4}^{+}}=K_{d} C_{N H_{4}^{+}}
$$

where: $K_{d}$ is the partitioning coefficient between soil solid and liquid phases $\left(L^{3} M^{-1}\right)$. A good approximation for the $K_{d}$ is gotten, using the cation exchange capacity $(C E C)$ as the unique input parameter (Lindström et al., 2010). The parameters $k_{m i n}, K_{d}, k_{n i t}, \lambda$ are taken, as described in Table 1.

\section{Equation of nitrogen transport in the water table}

The water table is characterized by saturated water content $\theta_{s}$ and a saturated hydraulic conductivity $\mathrm{K}_{s}$. The $\mathrm{NO}_{3}{ }^{-}$ions will behave as tracers and will be easily led to the water table. The strong absorption and rapid nitrification of ions $\mathrm{NH}_{4}{ }^{+}$to ions $\mathrm{NO}_{3}{ }^{-}$ make their probability to reach the water table insignificant. Given all these conditions, the nitrate nitrogen transport equation in the water table is given by Equation 14:

$$
\begin{aligned}
\left(\theta_{s}+\rho_{d} K_{D}\right) \frac{\partial\left(C_{N O_{3}^{-}}\right)}{\partial t}= & \frac{\partial}{\partial x}\left(\theta_{s} D_{\text {ap }} \frac{\partial C_{N O_{3}^{-}}}{\partial x}\right)-\frac{\partial\left(Q_{x} C_{N O_{3}^{-}}\right)}{\partial x} \\
& +\frac{\partial}{\partial z}\left(\theta_{s} D_{\text {ap }} \frac{\partial C_{N O_{3}^{-}}}{\partial z}\right)-\frac{\partial\left(Q_{z} C_{N O_{3}^{-}}\right)}{\partial z}+K_{\text {nit }} \theta_{s} C_{N H_{4}^{+}}
\end{aligned}
$$


where: $\mathrm{C}_{\mathrm{NO} 3}{ }^{-}$and $\mathrm{C}_{\mathrm{NH} 4}{ }^{+}$are the nitrate nitrogen and ammonium nitrogen concentrations.

At the lower boundary condition $\left(x=X_{\max }\right)$ and $\left(z=Z_{\max }\right)$ no boundary flux condition was used, wich is equivalent to Equation 15:

$$
\frac{\partial C_{i}}{\partial x} \mid=0 \text { and } \frac{\partial C_{i}}{\partial z} \mid=0
$$

Table 1. Soil hydraulic and transport parameters of the study domain

\begin{tabular}{c|c}
\hline Parameters description & Value \\
\hline Saturated hydraulic conductivity $K_{s}\left(\mathrm{~cm}^{2} / \mathrm{s}\right)$ & 0.00874 \\
\hline Pressure head scale parameter $\alpha\left(\mathrm{m}^{-1}\right)$ & -36 \\
\hline Saturated volumetric water content $\theta_{s}\left(\mathrm{~m}^{3} \mathrm{~m}^{-3}\right)$ & 0.4 \\
\hline Shape parameter $m(-)$ & 0.827 \\
\hline Shape parameter $\eta(-)$ & 6.2 \\
\hline Specific storage $S_{s}\left(\mathrm{~cm}^{-1}\right)$ & $4.6 \times 10^{-5}$ \\
\hline Effective porosity $\omega(-)$ & 0.38 \\
\hline Molecular diffusion in the soil $D_{0}\left(\mathrm{~m}^{2} \mathrm{~d}^{-1}\right)$ & $6.24 \times 10^{-5}$ \\
\hline Soil dispersivity $\lambda(\mathrm{cm})$ & 2 \\
\hline Mineralization potential rate $k_{\min }\left(d^{-1}\right)$ & $3.32 \times 10^{-4}$ \\
\hline Nitrification potential rate $k_{n i t}\left(d^{-1}\right)$ & 0.24 \\
\hline Cation exchange capacity $C E C\left(\mathrm{~g}^{-1}\right)$ & 100 \\
\hline Solid/liquid partitioning coefficient $K_{d}\left(\mathrm{~m}^{3} \mathrm{~kg}^{-1}\right)$ & $6 \times 10^{-3}$ \\
\hline
\end{tabular}

\section{Numerical model}

The flow and reactive transport equations, subject to their initial and boundary conditions, were solved by applying the finite element method. The Freefem ++ code was adapted to the problem needs (Hecht, 2012), namely: Richards equation to study the water flow in the unsaturated zone (Eqs. 5 and 6 ), the diffusivity equation for the groundwater flow and the transport equation of advection-dispersion type to study the nitrogen transfer in the unsaturated-saturated zone $(E q .10)$. The nodes are placed to the basin boundary at regular intervals (e.g. 20 nodes for a boundary of $200 \mathrm{~cm}$ ). The finite element grid is then automatically obtained, based on the Delaunay-Voronoi algorithm. The UMFPACK solver is used. The generated mesh can be automatically adapted to sensitive zones like infiltration band and the capillary fringe. A polynomial space of 0degrees for the flux and 1-degrees for the pressure, hydraulic head and concentration are used. The simulation was run with a time step of $2 \mathrm{~min}$ with a total time of $120 \mathrm{~h}$. Once the pressure head $h$ is computed in the unsaturated zone, $\theta$ and $q$ are calculated. The water content $\theta$ is used to calculate the rates of the biochemical nitrogen kinetics. Subsequently, the systems of equations describing the mass transport of $\mathrm{NH}_{4}^{+}$and $\mathrm{NO}_{3}{ }^{-}$ are composed and the amounts of mineralization and nitrification rates are evaluated to the $\mathrm{NH}_{4}{ }^{+}$system. Finally, the $\mathrm{NH}_{4}{ }^{+}$transport system for the ammonium concentrations and the $\mathrm{NO}_{3}{ }^{-}$transport system are solved. 


\section{Results}

\section{Model validation}

For the validation, the numerical simulations of the water table profiles are compared with experimental measurements obtained from a laboratory scale with piezometers for different times of recharge. The model was also validated using experimental data taken from the Vachaud's experiment (Vachaud et al., 1973). The above calculations were performed using the mean $K_{s}$-value (Fig. 2). Figure 3 shows a rather good agreement between the positions of measured and calculated water table profiles during the recharge periods at $3 \mathrm{~h}$ and $8 \mathrm{~h}$.
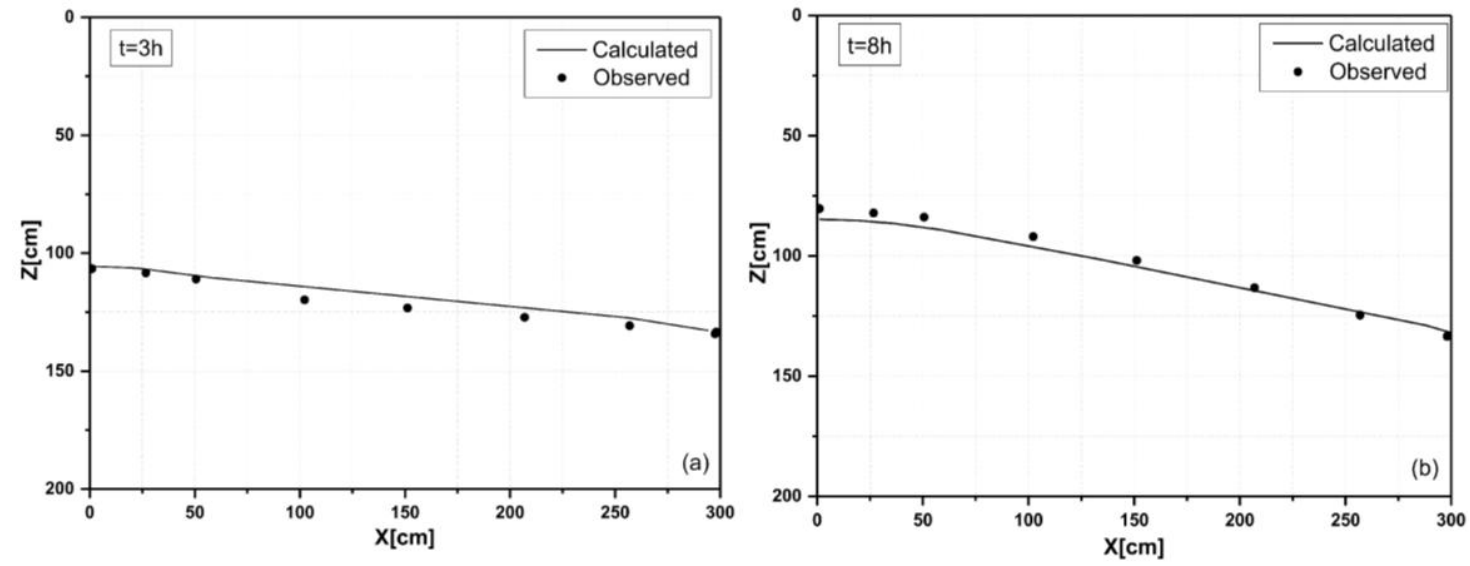

Figure 3. Comparison between computed and observed water table position at $3 \mathrm{~h}$ and $8 \mathrm{~h}$ (steady state condition)

When the wet front from the surface soil reaches the water table, the free surface starts rising. From that moment, the water table stabilizes over time to a maximum position. The aquifer is hydrostatically balanced and therefore the flow entering through the infiltration band becomes equal to that exiting through the outlet of the aquifer.

There is an important flow in the saturated portion of the soil above the free surface with values identical to those obtained under the free surface. It is interesting to note that capillary flow induces a significant vertical upward flow component in the unsaturated zone located above the free surface. The deformation of the flow lines has substantially a vertical component within the band of horizontal infiltration and below the free surface.

The model was validated on measures of nitrate concentrations drained by leaching at the outlet of the aquifer (Fig. 4). The experimental measurement and model simulation have a good agreement.

\section{Mesh adaptation}

Using Freefem++ code allows the resolution of equations characterizing transport phenomenon in a variably-saturated soils. The mesh refinement is carried out automatically during the recharge in areas that may be considered to be mathematical singularities such as: the infiltration band and the capillary fringe. This procedure improves significantly the quality of the results (Hecht, 2012). Figure 5 shows the areas affected by the auto-adaptive mesh refinement after the refinement procedure. 


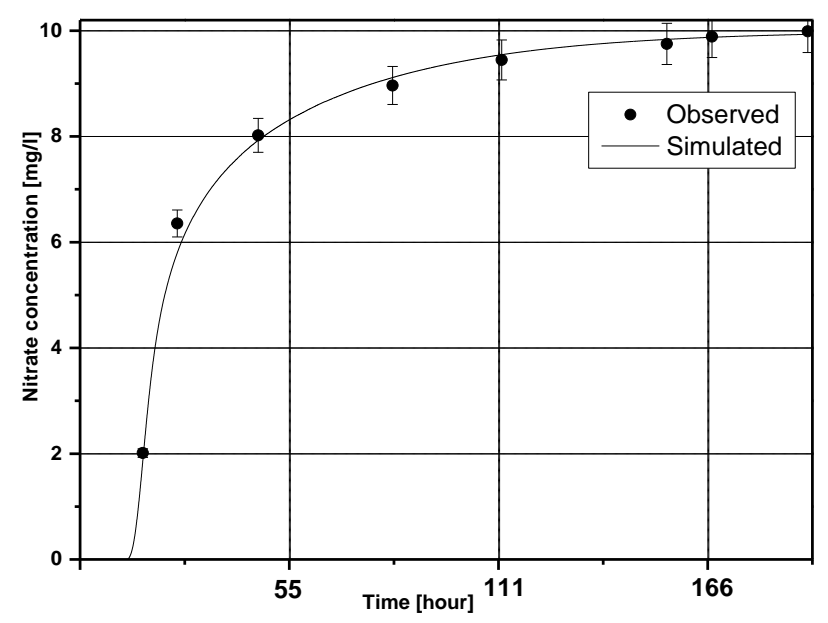

Figure 4. Measured and calculated quantities of leached nitrate at the outlet of the aquifer

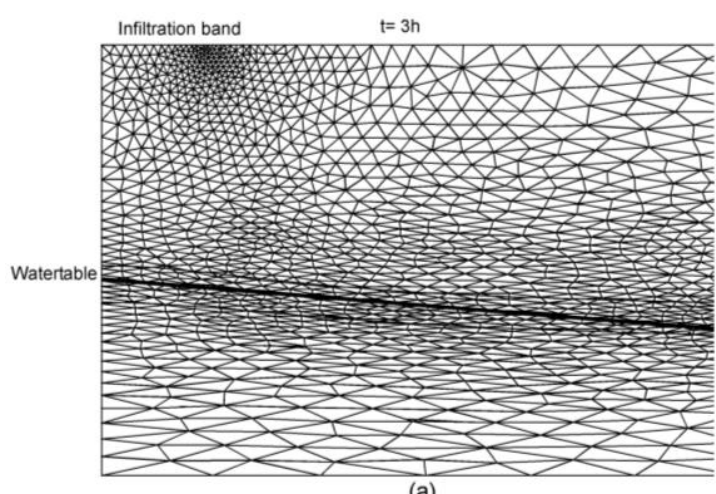

(a)

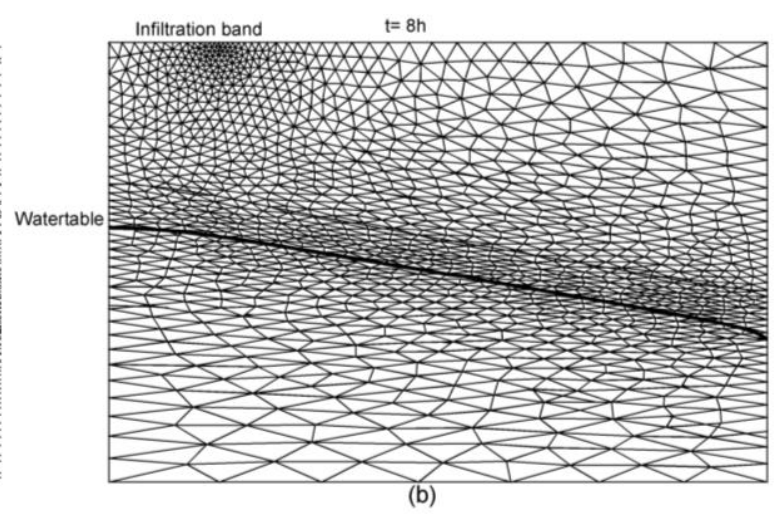

Figure 5. Self-adaptive mesh generated at the wet front and the capillary fringe at $3 \mathrm{~h}$ and $8 \mathrm{~h}$ (the steady state)

Classically, the numerical solution is checked with the exact analytical solution. However, in this case the gain for using the anisotropic mesh adaptation technique is evaluated by comparing numerical solutions denoted by $V_{m}{ }^{h}$, with the reference solution, $V_{m}{ }^{r e f}$ at steady state (Belhamadia et al., 2014), the following error is presented in Equations 16 and 17:

$$
E_{2}=\frac{\left\|V_{m}^{h}-V_{m}^{r e f}\right\|_{2}}{\left\|V_{m}^{r e f}\right\|_{2}}
$$

with:

$$
\left\|V_{m}^{h}-V_{m}^{r e f}\right\|_{2}=\left(h^{2} \sum_{i=1}^{m}\left|V_{m}^{h, i}-V_{m}^{r e f, i}\right|^{2}\right)^{\frac{1}{2}}
$$

Mesh adaptation has the ability to capture much more detail with more accuracy and a high order of convergence. It allows the generation of the optimum mesh size for a 
given accuracy with gains in $C P U$ time, memory and storage space. An extremely fine mesh is chosen as a referential mesh. The errors are in the $L_{2}$ norm. The results in the uniform and adaptive mesh are described in Table 2.

Table 2. Comparison of the error $E_{2}$ at $t=8 h$, number of dof (degrees of freedom) and number of triangles obtained with standard meshes and the adapted meshes (Freefem++)

\begin{tabular}{c|c|c|c|c}
\hline & \multicolumn{3}{|c|}{ Standard meshes } & Adapted $f f++$ meshes \\
\hline Meshes & (a) & (b) & (c) & (d) \\
\hline Nb of dof & 426 & 10028 & 39220 & 1238 \\
\hline $\mathrm{Nb}$ of triangles & 770 & 19654 & 77638 & 2348 \\
\hline Error & 0.674 & 0.163 & 0.096 & 0.114 \\
\hline Total CPU time & $25.527 \mathrm{~s}$ & $303.178 \mathrm{~s}$ & $1014.16 \mathrm{~s}$ & $47.639 \mathrm{~s}$ \\
\hline
\end{tabular}

It takes nearly 20 times for a very fine structured mesh to reach an error equal to that of the adapted mesh. On the other hand, a low structured mesh has a substantial error. The small error reflects the advantage of using the mesh adaptation. As can be seen, the adapted mesh has a reasonable $C P U$ time and a low computational cost. Even that the structured mesh (b) takes more time and computation, it is not as close to observations as the adapted mesh (d).

\section{Discussion}

\section{Accuracy-uncertainty}

The accuracy of the model was evaluated by calculating the root mean squared error (RMSE; Hill and Tiedeman, 2007). To construct the RMSE, we first need to determine the residuals. The residuals are the difference between the measured water table profiles and the predicted values at steady state and then use the RMSE as a measure of the spread of the $Z$ values about the predicted $Z$ value. Low $R M S E$ values indicate little difference between the predicted and observed variables, and thus indicate a more accurate model.

The RMSE of the model was then normalized (NRMSE) to the range of the parameter measurements. Normalizing the RMSE provided a context for the accuracy of the model given these ranges. NRMSE was on a scale of $0-1$, and gives the overall error of the model.

The statistical methods also included a calculation of the index of agreement (Skill). A skill parameter developed by Willmott and recently used in different modeling studies (Moriasi et al., 2007), was also considered to estimate the accuracy of the model. This parameter allows to take into account modeled and observed deviations around the observed mean to estimate the performance of the simulation. The value of (Skill) reflects the degree to which the calculated variation accurately estimates the measured variation. Perfect agreement between model and observations corresponds to a skill parameter of 1. MS Excel was used for statistical calculations. Equations 18, 19 and 20 present respectively the statistical indicators (RMSE), (NRMSE) and (Skill) defined as follows: 


$$
\begin{gathered}
\mathrm{RMSE}=\sqrt{\left[\frac{\sum_{\mathrm{i}=1}^{p}\left(\mathrm{Z}_{\text {meas, } \mathrm{i}}-\mathrm{Z}_{\text {pred, } \mathrm{i}}\right)^{2}}{p}\right]} \\
\text { Skill }=1-\frac{\sum_{i=1}^{p}\left(\left|Z_{\text {pred,i }}-Z_{\text {meas } \mathrm{i},}\right|\right)^{2}}{\sum_{i=1}^{p}\left(\left|Z_{\text {pred, }}-\bar{Z}_{\text {meas }}\right|+\left|Z_{\text {meas }, \mathrm{i}}-\bar{Z}_{\text {meas }}\right|\right)^{2}}
\end{gathered}
$$

where $Z_{\text {meas,i }}$ is the measured value and $Z_{\text {pred,i }}$ is the calculated value of water table level at $x . Z^{-}$meas is the mean measured by the water table level and $p$ number of measures.

As listed in Table 3, the RMSE values $(2.78$ and $3.28 \mathrm{~cm})$ indicate the low discrepancy between observed and calculated values. The skill indicator close to 1 shows the good performance of the model. The uncertainty of the model prediction has been estimated, the results demonstrate the good performance of the model and confirms the water table level prediction.

Table 3. Statistical indicators of the hydrodynamic model performance

\begin{tabular}{c|c|c|c}
\hline Statistical indicators & $\boldsymbol{R M S E}(\mathbf{c m})$ & NRMSE (-) & Skill (-) \\
\hline Validation (at 3 h) & 2.78 & 0.02 & 0.98 \\
\hline Validation (at 8 h) & 3.28 & 0.03 & 0.97 \\
\hline
\end{tabular}

\section{Sensitivity analysis}

Mathematical models are developed to approximate engineering, physical, environmental, social, and economic phenomena of various complexities. Sensitivity analyses ( $S A)$ determine parameters that are most influential on the model output. In this case, a sensitivity analysis was performed with respect to the soil shape parameters $(m$ and $\eta)$ and scale parameters $\left(\theta_{s}, \alpha\right.$ and $\left.K_{s}\right)$. These parameters were varied by $P_{0}-\delta \times P_{0}$ and $P_{0}+\delta \times P_{0}$, where $P_{0}=\left(m, \eta, \theta_{s}, \alpha\right.$ and $\left.K_{s}\right), \delta=20 \%$, compared to their experimental values. The deviation of the simulated water table level relative to the measured is then quantified. Figure $6 a, b$ shows the results of the sensitivity analysis for the water table. It can be shown that the model is more sensitive to the hydraulic conductivity $K_{s}$ than all other parameters (see Fig. 6).

This result shows that the hydraulic conductivity $K_{s}$ must be measured with the most precise way possible. A small error in $K_{s}$ can lead to a great water table level error as demonstrated in the sensitivity analysis. Figure $6 c, d$ shows the simulated $k_{\text {min }}$ and $N_{\text {org }}$ sensitivity for different times.

The variation of $\alpha$ and $n$ is not enough significant, so the three curves (simulated, $+20 \%$ and $-20 \%$ ) are matching. The parameters $k_{\text {min }}$ and $N_{\text {org }}$ has a little effect (only near the surface) on the sensitivity of the results. However, for an agricultural field with a higher soil organic nitrogen the results will probably be more sensitive to $k_{\min }$ changes. 

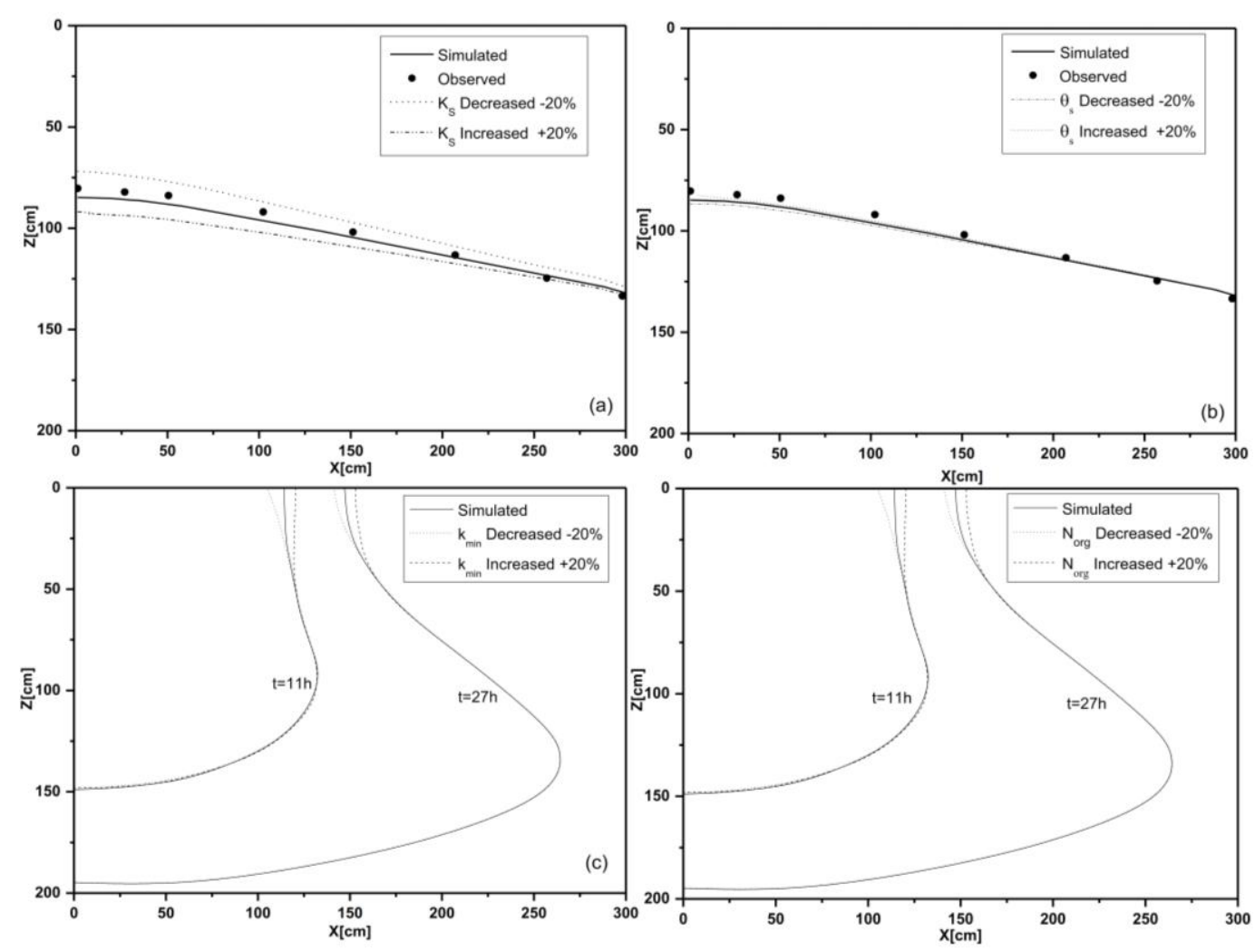

Figure 6. Sensitivity analysis of the water table position relative to $K_{s}$ and $\theta_{s} ; k_{\min }$ and $N_{\text {org }}$ mineralization sensitivity

\section{Nitrate transport simulation}

In Hénin-Dupuis model, $k_{\min }$ can take different values depending on the climate of the study area and the type of culture that is practiced. In the case of this study, the nitrate transport was tested in a laboratory scale model under controlled conditions (low organic matter and constant temperature).

Figure 7 shows the spatial distribution of simulated nitrate concentration $\mathrm{C}_{\mathrm{NO} 3}{ }^{-}$at different times. The transport simulation was run with a time step of 2 min with a total time of $120 \mathrm{~h}$. The leaching of nitrate is done with a relative delay to the flow, because of the flux imposed on the infiltration band during the recharge of the groundwater. The nitrate concentrations are important in the soil near the surface because of the application of nitrogen on the surface $10 \mathrm{mg} / \mathrm{l}$. These concentrations decrease with depth and their presence in the root zone is very important due to the mineralization of organic nitrogen in this layer and the rapid nitrification of $\mathrm{NH}_{4}^{+}$ions. These concentrations continue to decrease in the saturated zone and to be driven by the movement of the aquifer from the surface of soil to the outlet. The $\mathrm{NO}_{3}{ }^{-}$ions which behave as tracers are very mobile. They move easily in soil and appear in all depths of the basin with different concentrations, in accordance with literature (e.g., see Allred et al., 2007; Shekofteh et al., 2013).

\section{Nitrogen dynamics}

In this study, the effect of denitrification was omitted. Denitrification in soils requires a large population of denitrifying bacteria, electron donor compounds and 
anaerobic condition. Riparian areas can reduce nitrogen inputs to aquatic systems through plant uptake and microbial denitrification. For example, denitrification can be found along root canals where moisture and organic matter content are high or in anaerobic locations (Bechtold et al., 2006). In a field case, the nitrate concentration would not be well simulated by the model in riparian zones or areas with high denitrification. Indeed, this process can lead to a real transformation of nitrogen to gaseous forms (Maggi et al., 2008).
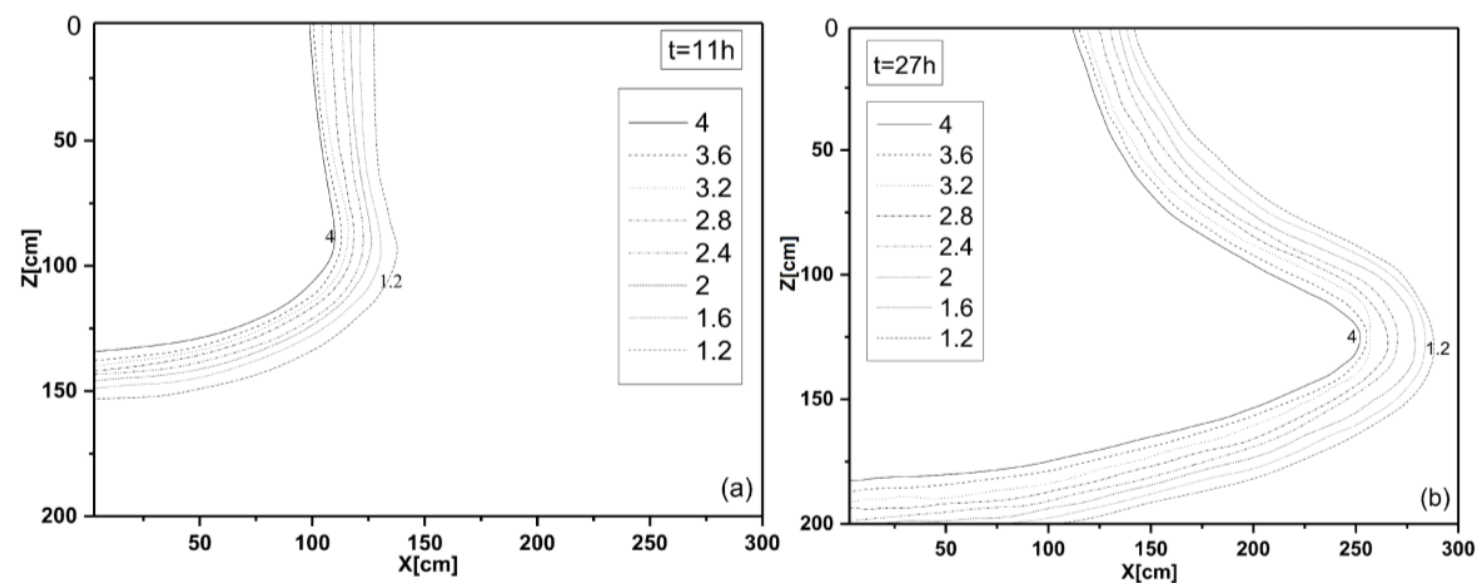

Figure 7. Spatial distribution of nitrate $C_{\mathrm{NO}}{ }^{-}$concentrations $(\mathrm{mg} / \mathrm{l})$ at $11 \mathrm{~h}$ and $27 \mathrm{~h}$

It is well established that bacterial activity controls the turnover rates of nitrogen mineralization. Indeed, several studies have shown that the mineralization of nitrogen varies linearly with temperature and soil $\mathrm{pH}$, two parameters that directly influence bacterial activity and population. Differences in mineralization dynamics between soils with identical characteristics suggest a difference in the microbial communities that populate them (Bechtold et al., 2006; Manzoni and Porporato, 2009). Soils containing high organic matter and bacterial activity generate a strong mineralization that does not affect the model but only the kinetics of transformation. The transport models require a global vision to fully evaluate the role of microbes in nitrogen dynamics.

Ammonification and nitrification were the primary processes affecting nitrogen in the unsaturated zone. Nitrification decrease in the unsaturated zone. In agreement with the experience of Hanson and Šimůnek in 2006 and its conclusion, the ammonium remained concentrated in the surface due to rapid nitrification. Ammonium was limited to upper place of the unsaturated zone with almost no presence near the water table. In contrast to ammonium, nitrate spread continuously downwards during the 5-day simulation period, as nitrate is not adsorbed and denitrification is negligible (Hanson et al., 2006). Thus, more than $97 \%$ of the nitrogen load discharged in effluent was transported to the water table, mostly as nitrate, due to the low level of organic matter in the soil and the small scale of our basin (Filipović et al., 2014; Maggi et al., 2008). However, as shown by Sâadi et al. (2003), The ammonium peaks at the soil surface disappear completely for depths far from the surface. Their probability of reaching the aquifer is nil. The high adsorption and rapid nitrification of $\mathrm{NH}_{4}{ }^{+}$ions near the surface are the main reasons for this. Hence, at agriculture sites constrained to similar conditions as in this study, most of the nitrate mass that leaches under the root zone will 
eventually reach groundwater. These results, obtained with the single-compartment model (Hénin-Dupuis), coincides with the results of the multi-compartment models (Manzoni and Porporato, 2009).

Different parameters can influence nitrate transport. The distribution coefficient $K_{d}$ is a constant that relates the sorbed nitrate concentration to the aqueous concentration. $K_{d}$ is strongly dependent on the amount of organic matter. Thus, an increase in $K_{d}$ will increase the amount of nitrate sorbed to the soil, resulting in less concentration reaching the groundwater. The experience of Ibnoussina et al. (2006) shows that the clay soil is characterized by a low nitrate transport. The nitrification rate constants were lower for the clay column than for the sand column.

Other Results of this study suggest that saturated hydraulic conductivity $K_{s}$ (related to pore size) may partly account for higher nitrate concentrations (Shekofteh et al., 2013). The thickness of the unsaturated zone also influence the nitrate transport. The deeper is the water table, the less is the nitrate contamination. The dispersion $D_{a p}$ also decreased with increasing water content, it suggest a more significant transport effect on the unsaturated zone than the saturated zone.

\section{Conclusion}

The present study focused on: (1) The development of a new mathematical formulation for water flow and nitrate transport prediction in unsaturated-saturated zones which are regarded as a single continuum, (2) A numerical model (i.e. Freefem ++ code) was used to study the water flow and nitrogen dynamics in the porous media. The self-adaptive mesh generation gives the numerical approach the capacity and efficiency to study singular areas with reduced CPU from $\sim 303 \mathrm{~s}$ to $\sim 47 \mathrm{~s}$. In addition, the advantage of the numerical model required a few variables, making the parameterization simpler. The obtained results from the model show a good-fit with laboratory observations data. On the other hand, the statistical indicators confirm the model accuracy. The sensitivity test shows that the hydraulic conductivity is more sensitive than water content (i.e. In hydraulic model); for transport model the $k_{\min }$ and $N_{\text {org }}$ parameters are sensitive in the root zone $(0-50 \mathrm{~cm})$.

Finally, It can be concluded that the developed model is a rigorous, practical and a useful forecasting tool, which can be used to simulate the transport of nitrogen in groundwater systems. It can also be used to design remedial systems such as bioremediation trenches. The approach used is simple and adaptable and thus can be applied to a real landscape scale situation. This implies that in a next step the model should be extended to a large field with seasonal periods and variably irrigation cycles.

\section{REFERENCES}

[1] Allred, B. J., Bigham, J. M., Brown, G. O. (2007): The impact of clay mineralogy on nitrate mobility under unsaturated flow conditions. - Vadose Zone Journal 6(2): 221-232.

[2] Bagarello, V., Iovino, M. (2012): Testing the BEST procedure to estimate the soil water retention curve. - Geoderma 187-188: 67-76.

[3] Bechtold, J. S., Naiman, R. J. (2006): Soil texture and nitrogen mineralization potential across a riparian toposequence in a semi-arid savanna. - Soil Biology and Biochemistry 38(6): 1325-1333. 
[4] Belhamadia, Y., Fortin, A., Bourgault, Y. (2014): On the performance of anisotropic mesh adaptation for scroll wave turbulence dynamics in reaction-diffusion systems. Journal of Computational and Applied Mathematics 271: 233-46.

[5] Bryan, N. S., Loscalzo, J. (2011): Nitrite and Nitrate in Human Health and Disease, pp 263-278. - In: Bendich, A. (ser. ed.) Nitrite and Nitrate in Cancer. Springer-Humana Press, New York.

[6] Butturini, A., Battin, T. J., Sabater, F. (2000): Nitrification in stream sediment biofilms: the role of ammonium concentration and DOC quality. - Water Res. 34(2): 629-639.

[7] Brooks, R. H., Corey, A. T. (1964): Hydraulic properties of porous media and their relation to drainage design. - Transactions of the Asae 7: 26-28.

[8] Cheng, Q., Chen, X., Chen, X., Zhang, Z., Ling, M. (2011): Water infiltration underneath single-ring permeameters and hydraulic conductivity determination. - Journal of Hydrology 398: 135-143.

[9] Deb, S. K., Sharma, P., Shukla, M. K., Ashigh, J., Šimůnek, J. (2016): Numerical evaluation of nitrate distributions in the onion root zone under conventional furrow fertigation. - Journal of Hydrologic Engineering 21(2): 05015026.

[10] Diaw, E. B., Lehmann, F., Ackerer, P. (2001): One-dimensional simulation of solute transfer in saturated-unsaturated porous media using the discontinuous finite elements method. - Journal of Contaminant Hydrology 51: 197-213.

[11] Dupuy, A., Razack, M., Banton, O. (1997): Contamination nitratée des eaux souterraines d'un Bassin versant agricole hétérogène-2: Evolution des concentrations dans la nappe. Revue des sciences de l'eau 10(2): 185-198.

[12] Filipović, V., Toor, G. S., Ondrašek, G., Kodešová, R. (2014): Modeling water flow and nitrate-nitrogen transport on golf course under turfgrass. - Journal of Soils and Sediments 15(8): 1847-59.

[13] Hanson, B. R., Šimůnek, J., Hopmans, J. W. (2006): Evaluation of urea-ammoniumnitrate fertigation with drip irrigation using numerical modeling. - Agricultural water management 86(1): 102-113.

[14] Hecht, F. (2012): New development in FreeFem++. - Journal of Numerical Mathematics 20: 251-265.

[15] Hill, M. C., Tiedeman, C. R. (2006): Effective Groundwater Model Calibration: with Analysis of Data, Sensitivities, Predictions, and Uncertainty. - John Wiley \& Sons, Hoboken, NJ.

[16] Ibnoussina, M. H., El Haroui, M., Maslouhi, A. (2006): Expérimentation et modélisation de la lixiviation de l'azote nitrique dans un sol sableux. - Comptes Rendus Geoscience 338: 787-794.

[17] Lindström, G., Pers, C., Rosberg, J., Strömqvist, J., Arheimer, B. (2010): Development and testing of the HYPE (Hydrological Predictions for the Environment) water quality model for different spatial scales. - Hydrology Research 41(3-4): 29.

[18] Maggi, F., Gu, C., Riley, W. J., Hornberger, G. M., Venterea, R. T., Xu, T., Spycher, N., Steefel, C., Miller, N. L., Oldenburg, C. M. (2008): A mechanistic treatment of the dominant soil nitrogen cycling processes: Model development, testing, and application. Journal of Geophysical Research: Biogeosciences 113: G02016.

[19] Manzoni, S., Porporato, A. (2009): Soil carbon and nitrogen mineralization: theory and models across scales. - Soil Biology and Biochemistry 4: 1355-1379.

[20] Maslouhi, A., Lemacha, H., Razack, M. (2009): Modelling of water flow and solute transport in saturated-unsaturated media using a self adapting mesh. - IAHS Publication P 331: 480-487.

[21] Moret-Fernández, D., González-Cebollada, C., Latorre, B., Pérez, V. (2015): A modified hood infiltrometer to estimate the soil hydraulic properties from the transient water flow measurements. - Journal of Hydrology 530: 554-560. 
[22] Moriasi, D. N., Arnold, J. G., Van Liew, M. W., Bingner, R. L., Harmel, R. D., Veith, T. L. (2007): Model evaluation guidelines for systematic quantification of accuracy in watershed simulations. - Transactions of the ASABE 50(3): 885-900.

[23] Mualem, Y. (1976): A new model for predicting the hydraulic conductivity of unsaturated porous media. - Water Resources Research 12: 513-522.

[24] Reynolds, W. D., Jeffrey, K. L. (2012): A drive point application of the Guelph Permeameter method for coarse-textured soils. - Geoderma 187: 59-66.

[25] Rezaei, M., Seuntjens, P., Shahidi, R., Joris, I., Boënne, W., Al-Barri, B., Cornelis, W. (2016): The relevance of in-situ and laboratory characterization of sandy soil hydraulic properties for soil water simulations. - Journal of Hydrology 534: 251-265.

[26] Saâdi, Z., Maslouhi, A. (2003): Modeling nitrogen dynamics in unsaturated soils for evaluating nitrate contamination of the Mnasra groundwater. - Advances in Environmental Research 7: 803-823.

[27] Saâdi, Z., Maslouhi, A., Zéraouli, M., Gaudet, J. P. (1999): Analyse et modélisation des variations saisonnières des concentrations en nitrates dans les eaux souterraines de la nappe Mnasra, Maroc. - Comptes Rendus de l'Académie des Sciences II A 329(8): 579585.

[28] Shekofteh, H., Afyuni, M., Hajabbasi, M. A., Iversen, B. V., Nezamabadi-Pour, H., Abassi, F., Sheikholeslam, F., Shirani, H. (2013): Modeling of nitrate leaching from a potato field using HYDRUS-2D. - Communications in Soil Science and Plant Analysis 44: 2917-2931

[29] Van Genuchten, M. T. (1980): A closed-form equation for predicting the hydraulic conductivity of unsaturated soils. - Soil Science Society of America Journal 44(5): 892898.

[30] Vachaud, G., Vauclin, M., Khanji, D. (1973): Étude expérimentale des transferts bidimensionnels dans la zone non saturée application à l'étude du drainage d'une nappe à surface libre. - La Houille Blanche 65-74. 